\title{
Development of Controlling System to Indoor Appliances using Mobile Device
}

\author{
Wan-Shing Yang ${ }^{1}$, Wen-Kuei Hsieh ${ }^{2 *}$, Yi-Sheng Yu ${ }^{3}$, Yao-Lin Huang ${ }^{4}$, \\ Wen-Hsu Hsieh ${ }^{5}, \mathrm{Yu}-\mathrm{Ying}$ Lin $^{6}$ \\ 1,3,4,5 Department of Computer and Communication Engineering, Hungkuo Delin University of Technology \\ New Taipei City, Taiwan, R.O.C. \\ yang@dlit.edu.tw, tony@mail.hdut.edu.tw, yaolinhuang@gmail.com,wen02@mail.hdut.edu.tw \\ ${ }^{2}$ Applied Foreign Languages Center, Hungkuo Delin University of Technology \\ New Taipei City, Taiwan, R.O.C. \\ wkhsieh@mail.hdut.edu.tw \\ ${ }^{6}$ Department of Business Administration, Hungkuo Delin University of Technology \\ New Taipei City, Taiwan, R.O.C. \\ roselin@ mail.hdut.edu.tw \\ * Corresponding Author
}

\begin{abstract}
This project develops an initiate system for remote control by using mobile device. Applying technology of the Internet of Thing, it is a practical integration between indoor appliances and mobile phone. Elements of the initiate system include Arduino uno, Bluetooth chip, infrared emitting element, and relay. Using Arduino as a core control, this initiate system operates fluorescent lamp or air conditioner by mobile phone App through Bluetooth interface.
\end{abstract}

Key words: Mobile Device, Arduino, Bluetooth, Infrared, Relay, Indoor Appliance Controlling

\section{Introduction}

In the age of advances in the internet of things, the connections among things enlarge our perception and provide more information that is useful to us. The technologies of the internet of things contain perception layer, network layer, and application layer. For the realization of intelligent living to human been in the future, these technologies are widely used in industry 4.0, smart wearable devices, home care, smart home, and internet of vehicle.

The advances of technology in the internet of things provide us more comfortable and safe life in the future. Applying the technology of the internet of things, this paper actualizes the controlling system among home appliances, microcontrollers, and controlling circuits. Based on this, remote home monitoring or smart house can be further developed.

\section{Background}

Relative technologies and modules applied in this paper described as follows:

\section{A. Arduino Uno}

In consideration of function, cost, and complexity, we apply Arduino Uno to complete this project. Arduino Uno is single chip microcontroller with advantages of open source codes and Processing/Wiring development environment which similar to environment of Java and C languages. Besides, with Arduino's fully equipped function modules, it is effective to develop prototype of hardware system. Table 1 presents the characteristics of ATmega328P chip. [1]

TABLE I

CHARACTERISTICS OF ATmega328P CHIP

\begin{tabular}{|l|l|}
\hline $\begin{array}{l}\text { Supports 7V to 12V } \\
\text { direct currents }\end{array}$ & $\begin{array}{l}\text { Supports 5V power supply by } \\
\text { Type B USB port }\end{array}$ \\
\hline $\begin{array}{l}\text { Analog voltage: } \\
\text { A0-A5 }\end{array}$ & $\begin{array}{l}\text { Digital I/O: D0-D13, among } \\
\text { them, D3、5、6、9、10、11 are } \\
\text { able to simulate DAC with } \\
\text { their PWM function. }\end{array}$ \\
\hline $\begin{array}{l}\text { Provides 131 } \\
\text { powerful commands }\end{array}$ & $\begin{array}{l}\text { Supports I2C and SPI protocol } \\
\text { interfaces }\end{array}$ \\
\hline EEPROM $(\mathrm{KB}): 1$ & Flash memory(KB): 32 \\
\hline $\begin{array}{l}\text { Temperature range: } \\
-40 \sim+85^{\circ} \mathrm{C}\end{array}$ & SRAM (KB) : 2 \\
\hline
\end{tabular}

B. Relay

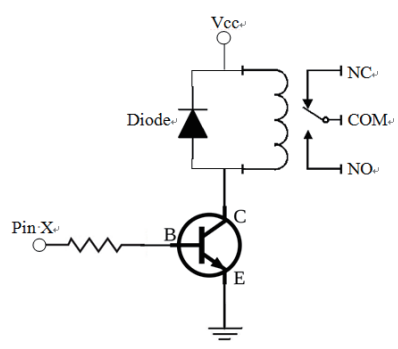

Fig. 1 Relay Circuit

Electric relay is a switch enables little electric powers controls larger electric power. By using relay, microcontroller or small voltage battery is able to switch $110 \mathrm{~V}$ home appliances such as bulbs. The input parts of electromagnet relay possess a set of electromagnet. When electromagnet electrifies, the magnetisms cause connection or disconnection 
of output contacts. When current disappears, output contacts restore to initial status. The output parts of relay contain normal open contacts (N.O.) and normal closed contacts (N.C.). When electromagnet electrifies, the normal open contacts connect to electromagnet, while the normal closed contacts disconnect to electromagnet. When voltages of microcontroller are insufficient, Amplifiers initiate relay, as Fig. 1.

\section{Infrared Sensors}

Infrared ray is invisible light and is widely used in short-range wireless transmission such as communication, detection, medical, and military. Sending specific coding through infrared communication technology and cooperating with connecting output pins of microcontroller to infrared transmitting circuit, this paper develops infrared sensors, i.e. infrared remote controller, to operate air conditioner, as Fig. 2 [2].

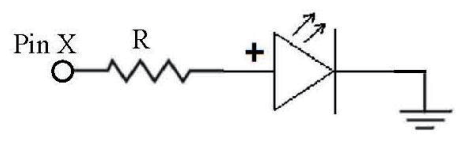

Fig. 2 Infrared Transmitting Circuit

\section{Communication Interface of Arduino $I^{2} \mathrm{C}$}

Consider intercommunication among Arduinos, we connect each Arduino with its SDA (pin 4), SCL (pin 5) and GND pin, as Fig. 3 [3]. To achieve interconnection among things, we transmit data from one to another Arduino with Wire database.

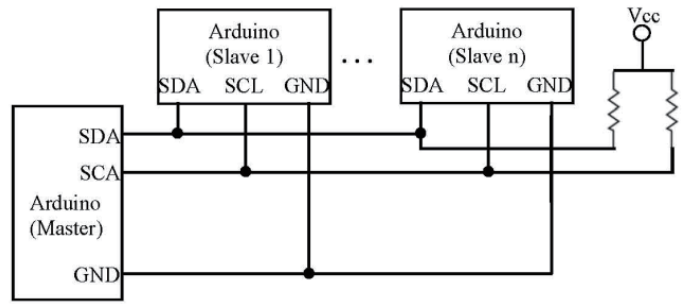

Fig. $3 \mathrm{I}^{2} \mathrm{C}$ Circuit of Arduino

\section{System Diagram}

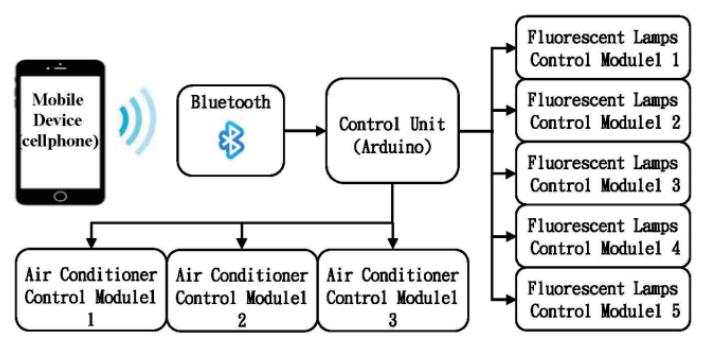

Fig. 4 System Diagram
This paper takes department laboratory as experimental case, as Fig. 4. There are three air conditioners and five fluorescent lamps in the laboratory. Sending commands through handheld device APP and transmitting commands to control unit, handheld device determines initiation/on-off to home appliance modules.

Adopting HC-05 serial transmission and SoftwareSerial.h component library, the control unit receives commands from handheld device and determines output signals to each home appliance.

\section{A. Fluorescent Lamp Controlling Module}

For fluorescent lamp controlling module, this project designs both manual operation and automatic control. As shown in Fig. 5, this project adopts single pole double throw (SPDT) switch by connecting to normal open contacts (N.O.) and normal closed contacts (N.C.) of relay.

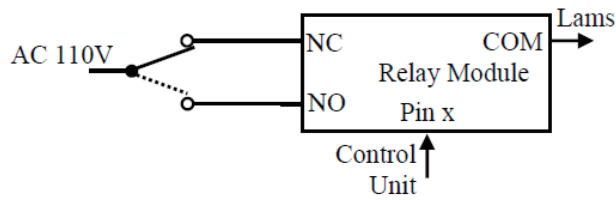

Fig. 5 Fluorescent Lamp Controlling Module

\section{B. Air Conditioner Controlling Module}

For air conditioner controlling module, this project adopts infrared appliances controlling. Transmitting set of specific coding by transmitter, the receiver (appliance) determines functions of air conditioners after receiving the coding [6]. Each air conditioner controlling module is consist of Arduino and an infrared transmitter. The control unit of I2C Circuit of Arduino receives commands from handheld device and determines functions to each air conditioner.

\section{Performance Analysis}

The space of actual measurement laboratory is $14.9 \mathrm{M} * 8.4 \mathrm{M}$ In the fluorescent lamp controlling module, with $\mathrm{DC} 24 \mathrm{~V}$ relay power and the distance from 50CM to $10 \mathrm{M}$, the coding are effectively transmitted between handheld device and the control unit with Bluetooth interface.

In air conditioner controlling module, the measurement results are validly confirmed under both the condition of transmission range less than $3 \mathrm{M}$ and the requirement of possessing three individual transmitting modules because each air conditioner requires its own infrared transmitting modules containing 15 optional functions each.

\section{Conclusions}

Arduino Uno is a single chip microcontroller with advantages of open source codes and Processing/Wiring development environment which similar to environment of Java and C languages. With Arduino's fully equipped function modules, it is effective to develop prototype of hardware system. Therefore, this paper develops hardware part of home appliance controlling system with Arduino and mobile phone App. With this controlling system, one can initiates both most 
of home appliances change over switch (COS), such as lightings, refrigerators, ovens, electric cookers, and infrared home appliances, such as televisions and air conditioners. To extension, this controlling system actualized the development of remote home monitoring and safety for smart home in the near future.

\section{References}

[1] Arduino Home, Retrieved from https://www.arduino.cc/ (Oct. 01, 2018)

[2] http://yehnan.blogspot.com/2013/05/arduino.html (Jun. 25,2018)

[3] An Introduction to Arduino

http://programmermagazine.github.io/201311/htm/article1.htm 1, (Jun. 01, 2018)

[4] ying-Jie Zhao (201X), An Introduction to Arduino Interactive Design, Flag.

[5] http://blog.cavedu.com/2014/04/04/\%E9\%9B\%99a\%E8\%A8\% 88\%E5\%8A\%83-part1\%EF\%BC\%9Aapp-inventor-\%E7\%B6 $\% 93 \%$ E7\%94\%B1\%Е8\%97\%8D $\%$ E7\%89\%99\%Е6\%8Е\%A7 $\%$ E5\%88\%B6-arduino-led-\%E4\%BA $\%$ AE\%E6\%BB $\% 85 /$ (Jun. 01, 2018)

[6] http://yehnan.blogspot.com/2013/05/arduino.html, (May. 1, 2018) 
Recent Developments on Information and

Communication Technology (ICT) Engineering- Meen, Yang \& Zhao ISBN: 978-981-14-2136-5 